\title{
WHEN CAN PUBLIC POLICY MAKERS RELY ON PRIVATE MARKETS? THE EFFECTIVE PROVISION OF SOCIAL SECURITY
}

\author{
Rebecca M. Blank
}

Working Paper 7099

http://www.nber.org/papers/w7099

\author{
NATIONAL BUREAU OF ECONOMIC RESEARCH \\ 1050 Massachusetts Avenue \\ Cambridge, MA 02138 \\ April 1999
}

This paper was prepared as the Frank Paish Lecture to the Royal Economic Society meetings in March 1999. Thanks are due to participants in that session, as well as to colleagues at Northwestern University and to Tony Atkinson for useful comments. The views expressed herein are those of the authors and do not necessarily reflect the views of the National Bureau of Economic Research.

(C) 1999 by Rebecca M. Blank. All rights reserved. Short sections of text, not to exceed two paragraphs, may be quoted without explicit permission provided that full credit, including ${ }^{\odot}$ notice, is given to the source. 
When Can Public Policy Makers Rely on Private Markets?

The Effective Provision of Social Services

Rebecca M. Blank

NBER Working Paper No. 7099

April 1999

JEL No. H11, I00

\section{ABSTRACT}

The privatization of social services is being increasingly discussed. The social services market is characterized by multiple market failures, including informational asymmetries, agency problems, externalities, and distributional concerns. Consumers may care as much or more about quality of services than about price. If quality is readily observable, the government can regulate private providers to assure standards are met. But when standards are difficult to observe or when the recipient is not the agent who makes the decisions, government ownership may be preferable. This paper categorizes the market situations in which the government provision of social services is likely to be most versus least attractive.

Rebecca M. Blank

Council of Economic Advisers

Old Executive Office Building

Washington, D.C. 20502

and NBER

rblank@nwu.edu

After July 1999:

School of Public Policy

440 Lorch Hall

University of Michigan

Ann Arbor, MI 48109-1220 
The pros and cons of privatization have been much discussed among policy-makers for many years, with the pros generally winning the debate as a growing number of once-nationalized industries in many countries have been privatized. Over time, these privatization efforts have expanded, from mining and transportation into telecommunications and electrical utilities. Even in the provision of social services, an area that has long had a tradition of extensive government involvement, there is a movement toward privatization. For example, as part of U.S. welfare reform states are giving contracts to for-profit firms to run job training and placement programs; a number of states are contracting out the management of prisons to private companies; some advocates have called for increasing privatization of elementary and secondary education through a school voucher program; and the U.S. debate over Social Security reform includes a variety of proposals to "privatize" Social Security, just as Great Britain's public pension system has allowed individuals to manage their own funds since 1987. This paper focuses on the social service sector, discussing the arguments for and against different degrees of government involvement.

Increased interest in privatization of social services may be due to a variety of factors. The wave of privatization and deregulation efforts in other sectors of the economy have led individuals to look for additional areas where such reforms may be applied. A public debate about low quality in some publicly-provided services (such as public education or welfare services) has led some to consider privately provided services as a possible alternative. Finally, the strong current concern with cost control in public budgets has led policy-makers to look for potential budget savings; as the social service sector takes up a significant fraction of public budgets, it has been scrutinized for ways to provide greater efficiency. 


\section{Current Government Involvement in Social Services}

"Privatization" is a ill-defined word, and as we will see below, there are a variety of ways in which the public and private sectors can interact (or not) in the provision of social services. Indeed, there is a wide divergence in the level and type of public versus private involvement in different social service areas. Fig. 1 indicates the extent of government ownership in a few key social service areas, and compares this with the share of revenues in these areas that come from the government. ${ }^{1}$ As Fig. 1 shows, government ownership is quite extensive in U.S. elementary and secondary education, where 89 percent of students attend publicly owned and operated schools, but is much less pervasive in the health care sector, where only 17 percent of hospital beds are in publicly owned and operated hospitals, or in the child care sector, where only 7 percent of child care slots are in government owned and operated facilities.

Government can be substantially involved in these areas in ways unrelated to ownership and management, as indicated by the divergence between financial involvement and ownership. The public sector is much more heavily involved in the financing of health care than in the ownership of hospitals, providing 62 percent of all hospital revenues, much of it through publicly-

\footnotetext{
${ }^{1}$ Sources for the data in Fig. 1: 1997 Hospital beds: American Hospital Association
} (1999) Hospital Statistics. 1997 Hospital revenues: Data provided by the U.S. Dept. of Health and Human Services (DHHS), Office of the Actuary, Health Care Financing Administration. 1995 Nursing home residents: G.W. Strahan (1997) 'An overview of nursing homes and their current residents.' DHHS, National Center for Health Statistics. 1995 Nursing home revenues: Data provided by DHHS, Office of the Assistant Secretary for Planning and Evaluation. 1995 E\&S enrollment and Post-Secondary enrollment: U.S. Dept. of Education, National Center for Education Statistics (USDE- NCES) (1997) Digest of Education Statistics. 1998 E\&S revenues: USDE-NCES (1998, forthcoming) Digest of Education Statistics. 1995 Post-Secondary Revenues: USDE-NCES (1995) Finance Survey. 1990 Child care spaces: E. Kisker, S. Hofferth, D. Phillips and E. Farquhar (1991) A Profile of Child Care Settings: Early Education and Care in 1990. 1996 Child care revenues: L. Stoney and M. Greenberg (1996) 'The financing of child care: current and emerging trends.' In The Future of Children, Vol 6(2). 
operated health care programs. In contrast, the public sector is less involved in the financing of higher education, providing only 38 percent of the revenues, although 78 percent of students attend publicly operated universities or colleges.

Fig. 1 presents data for only a few social service areas, but it raises the following question: Are these areas definably different from each other along some dimension that creates variance in the optimal mix of public/private involvement? Or are these areas quite comparable, so that only some archaic historical accident keeps the government heavily involved in some areas and not others? If the latter, then moving ahead with privatization within the social service area may be warranted. There are widely diverging opinions about the benefits of privatization in the social service area. For instance, a recent review of privatization by Shleifer (1998) concludes there are few arguments for extensive government ownership and management, even in areas such as education where this has long been the predominant institutional arrangement. In contrast, Starr (1989) argues that government ownership and management is a good thing in core social service areas, and is wary about privatization schemes.

This paper discusses these issues, focussing on three key questions: (1) What are the problems faced by the private provision of social services? (2) What are the alternative models of public sector involvement? and (3) Under what circumstances is government management and ownership likely to lead to a superior provision of social services?

\section{Alternative Models for the Provision of Social Services}

One of the characteristics of the social service sector is the prevalence of various forms of market failure. Indeed, one way to define "social services" is to characterize them by the 
following market attributes.

Externalities. Many social services generate benefits and costs that are greater than those accrued by the specific recipient of the services. Private markets are unlikely to take these benefits and costs into account, underproviding services which generate social benefits beyond the benefits received by the individual. For instance, ineffective or poorly run prisons may increase the probability of criminal behavior among prisoners after they are released, imposing costs on the larger society. Effective elementary education may benefit the entire society by assuring more literate and numerate future workers, raising productivity and (it is often argued) improving citizen awareness in a democratic society.

Informational Asymmetries. Effective private markets presume fully-informed consumers making choices. In many social service areas, it may be difficult for the recipient to judge the quality of the service provided. There are several reasons for this. Many social services are complex, with multi-faceted inputs and outputs. For instance, this is surely true of education or hospital care. In addition, some social services are hard to monitor, such as nursing home care or child foster care. Some services may be only infrequently purchased, such as many health procedures, which limits the information consumers have about them. All of these issues create asymmetries in information, and limit the ability of the recipient of the service to fully identify its quality.

Agency Problems. In many social service areas the recipient of the service may have a limited capacity for choice and is often not the actual decision-maker. For instance, young children are not able to make serious decisions; very ill or incapacitated persons may be in the same situation. For somewhat different reasons, prisoners in the criminal justice system are also 
without agency or choice. In these cases, the person making decisions is likely to be someone other than the recipient. While in some cases, the decider may have only the best interests of the recipient in mind (i.e., many parents care deeply about the quality of their children's education), it cannot be assumed that the best interests of the recipient will always be maintained by another individual. In this case, the private market decisions of the decider may not produce optimal outcomes for the recipient.

Distributional Concerns. Distributional issues are often a fundamental reason why private market outcomes are considered inadequate in the social service area, particularly if some people have limited incomes and are thus excluded from certain markets. At one level, this may imply a concern about access. For instance, Tobin (1970) discusses the principle of "specific egalitarianism", the view that some scarce commodities (health care, education, access to justice) should be distributed less unequally than the ability to pay for them. A stronger level of concern relates to equity in the receipt of services. In this case, it is not just access to but the equal or universal provision of a service that is desired. For instance the difference between these two distributional perspectives is highlighted by the debate in the United States between those who think publicly provided health insurance should guarantee access to a minimal set of health care services for low-income families versus those who want the government to provide similar levels of insurance to all citizens.

In many social service areas, these four problems occur in tandem. It is not difficult to name a variety of areas (education, health, child care, welfare) in which there are externalities, informational failures, distributional concerns, and potential agency problems all at the same time (i.e., see the discussion in Poterba, 1996). In these cases, as a body of literature in economics has 
indicated, the standard economist's presumption in favor of the unregulated private market will no longer hold and government involvement in one form or another may result in a better outcome (Sappington and Stiglitz, 1987; Greenwald and Stiglitz, 1986).

There are, however, many ways for the government to be involved in the provision of social services, and simply saying that there are market failures does little to indicate exactly what type of government involvement may be optimal. At least four broad alternative models may be identified.

Private ownership and management with government regulation. This is the model utilized in many sectors of the economy in which there are problems of market failure that can be readily corrected by government regulation. For instance, the externalities related to emissions of dirty water or smoke are corrected through various regulatory schemes; or informational problems in financial markets are dealt with through mandatory disclosure rules. If effectively implemented (this is an important and often unmet caveat), such regulatory schemes can produce a more optimal outcome than would the unregulated market.

Private ownership with (perhaps) government regulation and government funding to subsidize low-income clients. This is the standard "voucher" model, in which the government provides some redistribution of income among potential recipients, but the recipients themselves contract for services in the private market. For example, Section 8 housing vouchers in the United States provide low-income families with a subsidy that they can use for rental housing (subject to certain quality standards.) Food Stamps provide a voucher for low-income families that can be used to purchase additional foods at the grocery store. These voucher programs solve distributional concerns by providing access to low income families without interfering with the 
efficiencies of the private market.

Government ownership, with contracts to the private sector for the management and operation of the service. This type of shared public/private responsibility is typically what "privatization" in the social service area refers to. It is the way privatized prisons and privatized job training programs operate. As we will discuss below, a key issue in this approach is whether or not the government can write complete contracts with the private sector, to assure that the desired quality of service is provided and/or that full access is provided to all groups. Note that the government can implicitly redistribute income in this situation by funding the private contractor to assure that the service is available to all groups.

Government ownership and government management. In this case the government makes all operating decisions and government employees typically provide the service. Traditionally, prisons, schools, and welfare services have been provided in this way.

The next section provides a framework for deciding what level of government involvement may be most appropriate.

\section{How to Choose Among These Alternatives?}

There has been little formal modeling of the decision framework for deciding on the appropriate involvement of government in a market characterized by the market failures common in the social service sector. (An important exception is Hart, Shleifer, and Vishny (1997).) Like much other work, this paper will provide only an informal sense of how the key elements might fit together.

Assume that social services have both a price and a quality component. The price signal is 
readily observable, but the quality signal is not, for reasons discussed above. While the private sector may be more efficient at providing lower cost service, it may also provide lower quality, particularly when there are both information problems and agency problems. A private provider could potentially exploit both the lack of information on quality by the recipient, as well as any lower level of concern exhibited by the decision-maker for the recipient and offer lower quality services (at a lower price). In this situation, government-provided services may be less efficient (a point I'll return to later) but could provide higher quality if the government does not take advantage of these market failures. In cases where the loss of quality in a purely private market is high and/or where the inefficiencies associated with government provision are low, the government may be the preferred provider.

In fact, in some circumstances inefficiency itself is viewed as a signal of "caring" or higher quality services (Schlesinger, 1998). Friend and family relationships are often characterized by highly inefficient interactions, such as a willingness to listen to someone talk about their personal problems for the twentieth time or to sit for days by the bedside of an ill person. Service providers who are willing to provide this type of caring behavior may face higher employment levels and labour costs than is strictly necessary for the minimal provision of the service, but may be judged higher quality providers. For instance, nursing staff who have time to chat with patients and to "drop in" just to check on them, while also attending to their medical needs, may provide better care. Welfare case-workers who have time to talk with clients and learn about their family problems may be better able to help them move into employment. All of this suggests that there may be an efficiency/quality trade-off in the provision of social services. If these quality issues are not fully observable or not fully incorporated into decision-makers' behavior, the 
private sector may opt to produce services at a lower price but also at a lower quality level.

This suggests that there are three key issues in determining the appropriate form of government involvement: (1) How bad are the information problems? Or, stated another way, how observable/measurable is the quality component of the social service? (2) How big is the agency problem? and (3) Are distributional issues a concern?

Table 1 provides a simple schematic that indicates how the answers to these three questions can be used to characterize the situations under which each of the four levels of government involvement may be most useful. If output quality is observable, and there are no agency or distributional issues, then some form of government regulation, designed to deal with externality problems, seems the appropriate response. For example, if the only market failure in the educational area were the positive externalities associated with an educated population, then mandatory child schooling laws might be the only government involvement necessary in the educational market. In general, there are few social service areas where distributional concerns are absent, so this situation probably characterizes other markets far better than the social service area.

If output quality is observable and there are no agency issues, but there are distributional concerns and externality concerns, then voucher schemes (perhaps combined with some regulation) seem appropriate. For example, this situation appears to characterize the housing market and is a justification to expand housing vouchers (and decrease government involvement in the ownership of public housing.) If one believes that parents have only the best interests of their children in mind and that school quality differences are readily observable, then the argument can be made for school vouchers (along with some quality or quantity regulation to address 
externality problems) without government ownership or operation of the schools.

If output quality is observable, but there are both agency and distributional problems as well as externalities, then privatization via "contracting-out" may be viable. In this case, the government, because it actually owns the service, can write extensive contracts for a private manager that assures quality standards are met, access and equity issues are addressed, and appropriate decisions are made for those unable to decide for themselves. The key point here is that the nature of the service provided is observable enough that the government can assure a contractor is meeting the desired standards. ${ }^{2}$ An example of this may be job training programs, where both the inputs and the results are reasonably measurable. Of course, there are a number of situations meeting these criteria where the government has traditionally owned and operated services rather than contracting out. These are areas where privatization might be considered.

When it is hard to write a contract to assure quality and there are agency issues, distributional issues, and externalities, then government ownership and provision of services may be preferred. In this case, there is no way to "contract out" the work and assure that desired standards are met. Agency problems mean that the government must be heavily involved in decision-making regarding the recipients of services; combined with the informational asymmetries, government operation of the services may be the only way to guarantee adequate quality. For instance, those who support public schools and oppose vouchers tend to argue either that parents can't adequately make educational choices (information problems) or that parents won't make such choices (agency problems), and hence publicly owned and operated schools are

${ }^{2}$ The extensive reliance of the public sector on not-for-profit organizations in the United States to operate publicly funded programs provides many examples of this type of arrangement. See Salamon and Anheier (1998) for a description. 
preferable to private schools funded through vouchers.

Clearly, the information and the agency problems are key to deciding if government ownership and management is justified. Much of the disagreement about the appropriate public/private role is an argument about the extent or nature of the agency and informational problems in the social service market. I turn now to a brief discussion of these two issues.

Agency problems. If one can't trust the recipient of services to make his or her own choices, and if one does not trust the choices of other individuals to be in the recipient's best interests, then the government has traditionally stepped in as guardian to act "in loco parentis," and make decisions for the recipient of services. The key assumption here is that the government can represent the interests of the affected agent better than other actors, an assumption often characterized by its critics as a belief in governmental paternalism.

There is substantial disagreement on how severe the agency problem is in certain settings. For instance, there is disagreement over whether parents can best make all schooling decisions for their children, or whether children can best decide everything about an elderly parent's care. Those who argue against heavy public involvement in these realms are typically content with regulation designed to address the most serious outlier problems (i.e., removing children from abusive family situations, or preventing relatives from withdrawing life support without medical approval.)

Questions about agency are prevalent throughout the debate about effective social service provision, however, and relate to far more than children and the incapacitated elderly. For instance, since Social Security was established in 1938, there has been an ongoing debate in the United States over the ability or willingness of individuals to make appropriate long-term savings 
decisions for retirement, and whether the government should properly mandate such savings through a public pension system. In quite a different realm, the welfare reform discussion over the past 10 years in the United States has included a debate about whether women on welfare become "dependent" and lack the motivation to act in their own long-run best interests (i.e., to seek economic self-sufficiency).

In all of these cases, the question is whether one can trust individuals in the market to make appropriate choices or whether there is a role for a more omniscient (and thereby more powerful) government to actively intervene in decisions. While economists tend to be skeptical of arguments against individual choice, the social service area provides more situations that provoke debate than many other markets.

Output observability. The ability to observe and monitor quality is important to the presumption of informed individual choice or for effective government contracting with the private sector. There are a number of examples where governments have tried to contract with private agencies for services, and been unable to adequately monitor and observe the quality of the services provided. For example, Hart, Shleifer, and Vishny (1997) cite examples where prison privatization appears to have resulted in lower costs but greater violence within the prison. Occasional headline-making stories about private foster care settings in which children are abused are another example of failed "contracting" by the government. These examples are often cited as arguments against privatization.

But the existence of information problems and the difficulty in observing quality need not necessarily lead to the presumption that the government rather than the private sector should provide the service. There are at least two ways to argue that even in the presence of these 
problems the private sector can be an effective provider. First, it may be that observable measures of quality are only developed over time with experience. A demand for such measures by the government may provide an incentive for the private sector to develop credible measures. Indeed, one can see this occurring in regulated health care markets, where cost pressures have resulted in ongoing government demands to justify existing price levels, which in turn has generated a number of new measures of output and quality. In this situation, the absence of decent quality measures may only be a short-run rather than a long-run problem in the market, but such measures will not be developed unless the private sector is incentivized to provide them.

A second response is that even if output is not directly observable, there may be ways for the private sector to credibly signal quality to users. Many have argued that this is behind the preference for not-for-profit versus for-profit providers that appears to exist in many social service areas in the United States (see Weisbrod, 1988). An institution incorporated as a not-forprofit may be assumed to be reinvesting its surplus in providing higher quality services rather than in enriching the owners. ${ }^{3}$

Clearly private institutions, such as hospitals or educational institutions, can do things to signal the quality of their services, as the game theory literature discusses. Institutions can engage in reputation-building, or can undertake exceptional information sharing. In a market where large institutions make long-term investments (such as the health care market), the unobservability of quality by an individual for any specific service or procedure may not be a serious problem if there are credible institutional assurances that quality standards are being

${ }^{3}$ The relative roles of not-for-profit versus for-profit service providers is a fascinating subject in itself. The evidence on whether not-for-profits actually provide higher quality services than for-profits is mixed (Hansmann, 1996; Weisbrod, 1998; and Schlesinger, 1998). 
maintained.

These counter-arguments suggest reasons why the simple schematic in Table 1 may be inadequate. Even when output is unobservable and full contracts cannot be written, there still may be circumstances in which private ownership and management can effectively balance both efficiency and quality concerns.

\section{Why Might the Government Maintain Higher Quality?}

Even when the private sector too strongly emphasizes price over quality, it may not be immediately clear that the government will do better. In fact, the worse case scenario may occur when the public sector provides a service at higher cost, but with as low or lower quality than the private sector. Stories about highly paid government employees who never show up at work provide evidence that this can occur.

Obviously, if the government can and does monitor its own performance better than it could monitor the performance of a private contractor, then government provided services may be higher quality, particularly in cases where there are strong asymmetries of information between provider and client. The government, by internalizing both provider and client decisions in one entity -- setting standards as well as delivering services -- should avoid the exploitation of the asymmetry that might occur in the private market. (It is worth noting, however, that little formal attention has been given to how a market might operate when one entity makes both supply and demand-side decisions. This is essentially the role filled by government when the public sector both defines what the service is that will be provided and determines who is eligible to receive it. While there are models of political decision-making that are relevant to this situation, the 
economics are less well understood.)

One key question is whether the government can induce higher quality or more "caring" behavior from its employees than the private sector. One of the arguments for professionalization in social services is that professionals have a reputation invested in the appropriate delivery of services, and will do the job better than someone who has less personal investment in outcomes. But the private sector can hire professionals, just as the government hires them. There are, however, at least two circumstances in which government employees might deliver higher quality services.

First, the government may be able to motivate employees by valuing "public service," that is, by valuing the non-price aspects of the service provided and the job done by the employee. Certainly there is a "civil service culture" in many public agencies, where people accept wages lower than they might be able to command in the private sector because they find the work and the mission of the public agency compelling. Indeed, one of the concerns often expressed about privatizing welfare caseworkers, is that it would "monetize" the job, placing greater emphasis on efficiency and price-related aspects of the job, and removing employees' ability to "care" for their clients by giving them extra time or attention. Of course, it is a valid question why government should be uniquely able to incentivize people to care. Certainly a number of private companies at least claim that their employees have a caring attitude toward clients, and reward employees who evoke particularly high levels of customer satisfaction.

A second way in which government may be able to deliver higher quality services is if it is able to attract particularly high quality workers. One way to do this is to pay higher-than-market wages, and there are situations where queues for public employment clearly indicate that the 
government is paying above market wages. But in the social service area, it is rare to see the government paying higher than average wages. In fact, in many cases just the opposite occurs. In this case, if the government can combine high competency or educational requirements with low monetary rewards, this will attract only those persons who highly value the job and the service that it provides. (Of course, if the government simply pays low wages without imposing high standards, the result will be incompetent employees.)

The government can play this game and attract committed workers only if it has some labour market power. For instance, if the government has monopsony control over workers, and is the only employer of social workers or teachers, then it may be able to elicit a particularly high quality work force at relatively low wages. Alternatively, historical discrimination in the private sector against women and minorities may have increased government's market power in hiring these groups in the past. The willingness of the government to hire such workers as teachers or nurses, when they had few other professional options, attracted many high-quality workers into the teaching and nursing fields. Particularly as the labour market for women has opened up, the ability of the government to hire higher quality female workers at low wages has lessened. At least some have claimed that the quality of educational services has eroded as the government lost market power in hiring professional women. ${ }^{4}$

A last comment about the ability of government to provide quality services is worth making: The more that one cares about enforcing "universalism" in the provision of services, the stronger the argument for government provision. One of the strengths of government is its

${ }^{4}$ It is worth noting that the private sector has been effective at playing this game as well in a few areas. For instance, the market for ministers is also characterized by high educational requirements and low wages, hence attracting only committed individuals. 
ability to enforce common standards (such as a common curriculum in the schools) or equallyavailable services (such as equal treatment in the courts). ${ }^{5}$

In some social service areas, one may want to avoid self-sorting and stratification among customers. For instance, if the schools are expected to provide assimilation across groups, then it is undesirable to allow people to sort themselves into separate schools by income, by religious belief, or by other tastes. Hansmann (1996) notes that education is often considered an "associative good", in which the other students affect one's own outcome (unlike health care, where the characteristics of a doctor's other patients probably have less effect on one's own care.) Kremer and Sarychev (1998) explicitly note that school vouchers will allow greater ideological sorting, and will allow individual schools to particularly cater to specific educational tastes. If one believes that there are social welfare advantages from economic and social diversity at public schools, or if one believes that there are specific uniform curriculums or standards that all children should be taught, then the argument for publicly operated schools is much stronger. In short, if universalism in the provision of services is considered important, then government provided services are likely to be preferred because of the greater control that government can exercise to assure universal standards are met. ${ }^{6}$

\section{When is Government Management Less Attractive?}

${ }^{5}$ Stiglitz (1989) notes that the state has two particular powers, that of compulsion and universality.

${ }^{6}$ In many cases, the arguments about universalism in the public versus private provision of social services -- particularly schools and medical care -- are also overlaid with a debate about the secular versus the religious provision of such services. 
If the above section discussed the conditions under which the government might do a particularly good job of providing higher quality services, and therefore be a preferred provider of social services, this section discusses situations when government management might be less attractive -- even in cases where the quality of services provided by government is somewhat higher.

First, government inefficiencies might become large enough that even with somewhat higher quality, the cost of allowing government management offsets the benefits. As Stiglitz (1989) has noted, "public management" is itself a public good, and one that is often hard for voters to easily observe. Wolf (1988) reviews a large number of studies on the comparative efficiency of the public and private sector, noting that most -- but by no means all -- of them conclude the private sector is able to operate at lower (in some cases very much lower) costs. ${ }^{7}$ Few of these studies focus on social service areas, however. Poterba (1996) notes that it's not clear that the government is markedly less efficient in comparison to the non-profit sector, which provides the primary private-sector alternative to the public sector in many areas of social services in the United States.

Second, the more that government is plagued by patronage and corruption problems, the less attractive is the government management of services. Such problems may be one particular reason why the government is less efficient, but they are likely to also affect the quality of services provided, as well as the extent to which the government meets public goals about access and equity in the provision of services. Of course, it is worth noting that corruption in the public sector in many countries often mirrors corruption in the private sector. In this situation, it's

\footnotetext{
${ }^{7}$ See also Vining and Boardman (1992) for an extensive discussion of this issue.
} 
unclear which sector is the preferred provider of services.

Third, the government may be ineffective in providing higher quality services. Poor management and inefficiencies in the public sector may be causally related to low quality services, in which case the price/quality tradeoff posited above is an inaccurate characterization; lower prices and higher quality may be complements rather than substitutes. Indeed, in cases where the public sector underpays workers relative to the market, or provides particularly bad managerial oversight, the quality of government-provided services may be very low. (There are plenty of examples of this in my current hometown of Washington, D.C.) The lower the quality of publicly-provided services, the less apparent force there is to the argument that the private sector will provide services at too low a quality level. As Wolf (1988) has noted, there is extensive "nonmarket failure" in government, just as there may be market failure in the private sector.

This argument is particularly cogent when the primary reason for government management centers around the public desire for equal access or equal provision of a particular service. If large differences in access or quality emerge under government provision, the less persuasive the argument for extensive government involvement. For instance, the problems that have plagued inner city public educational systems in the United States have clearly eroded support for traditional public school systems, and are a primary reason why many supporters of vouchers argue for greater privatization in schools. When the public schools are heavily segregated by race and income and face wide disparities in resources, arguments for government control in order to enforce assimilation and common standards become weaker. When the public schools provide poor quality services and fail to educate students adequately, arguments that the government should control educational choices because of agency problems in educational choice among low- 
income families become weaker.

The inability of government to provide higher quality or more equitable services may be due to poor public management. But it may also be due to erosion in the things that have traditionally allowed government to maintain higher quality services. For instance, if the general level of trust in government erodes, and fewer people believe that "public service" has a positive meaning, then government may not be able to elicit a more caring response among its employees than the private sector. Alternatively, if the market power that government had in the labour market erodes, as discriminatory barriers in the private sector decline, then the government may be less able to hire high quality workers at lower wages. Arguably, both of these things have happened in recent years, perhaps providing one reason for the increased interest in greater private provision of social services.

Finally, it is worth discussing the role of competition in the provision of social services. Economists often take it as obvious that competition will improve the market, and indeed there is substantial evidence that greater competition in markets does reduce inefficiencies. There is, however, little evidence on the role of competition in the provision of social services. In reviewing the evidence for school vouchers, Levin (1998) notes that the evidence in favor of competition is relatively weak. The key issue is whether competition, despite it's positive effects on efficiency, may have negative effects on quality.

Particularly when quality is hard to observe, competition is likely to focus on price-related issues. As noted above, increased emphasis on price may produce lower quality for social services. For instance, Schlesinger (1998) notes that increased competition among hospitals (particularly the entry of for-profit hospitals into areas dominated by not-for-profit hospitals) 
changed the way in which the not-for-profits operated. The not-for-profit hospitals came to behave increasingly like the for-profits over time as the for-profit hospital share increased. One effect was a reduction in uncompensated care by the not-for-profits.

Competition may also be less attractive in circumstances where equity and universality concerns are strong. By its nature, competition often allows markets to stratify, with particular products aimed at the tastes of consumers with different preferences. For example, competition in the schools is likely to allow individuals with extreme preferences more choice, thus leading to a situation where parental ideology has a greater impact on children's education. Those who highly value individual choice may find this a preferable outcome. But those who believe more strongly in the role of schools as an assimilating institution, with common curriculums, may find this outcome less preferable.

This suggests that competition -- while almost surely a guarantee of greater efficiency -may have other offsetting costs which should also be considered. Some have argued that government should create greater competition for itself by increasing consumer choice in publiclyprovided goods, by encouraging cross-jurisdictional competition, or by privatizing at least part of the market. The full effect of such reforms is typically not well-understood.

\section{Conclusion}

Few people disagree that some government involvement in the provision of social services is necessary. But there are a wide range of viewpoints about the preferred nature of public involvement. The narrower view is that some forms of regulation, together with income supplementation or vouchers, is typically as far as the government should go. The broader view 
argues for much greater government control, ownership and management in at least some areas. These disagreements can often be characterized along the following dimensions:

The degree of concern with agency problems and the degree of belief in government's ability to be wisely paternalistic. The more strongly one believes that neither recipients nor their families can make effective decisions, and the more strongly one believes in the ability of the government to improve individual or social outcomes by intervening in individual choices, the more likely one is to support more extensive public involvement in the social services.

The degree of concern over the difficulty in collecting and disseminating information on quality of services. The more that one believes measurable standards of quality can be observed in the social service field, the stronger the argument for government regulation of the private sector rather than government management or ownership. The more that one believes that nongovernmental agencies can provide credible signals of quality in a particular market, because of their long-term reputational concerns, or because of the nature of the market, the less the role for government ownership or management.

The extent that equity and universalism are emphasized. The more highly one values universal standards for a service, or that one desires all persons to receive identical services, the stronger the argument for public ownership and management. The more that stratification, sorting, and differential taste-based choices are preferred, the stronger the argument for private ownership and management.

The level of trust in the public sector. The more that one believes the public sector to be effective, with good public management and without problems of corruption, the more likely one is to believe that the government can provide higher quality social services without losing too 
much in efficiency. Similarly, the more one believes in the motivating factor of public service and the ability of government to elicit strong commitments from their workers, the higher quality services one is likely to expect from the public sector.

Honest people -- and honest economists -- can validly disagree about how they evaluate these issues. My own evaluation leads me to believe that there remain a number of areas where the direct government provision of social services is not obviously worse than, and -- along at least some dimensions -- may be better than more privatized arrangements. The unique nature of the social service area, with multiple forms of overlapping market failure, provide an opportunity for effective government involvement that may not be justified in many other sectors of the economy. 


\section{References}

Greenwald, B. and Stiglitz, J. (1986). 'Externalities in economies with imperfect information and incomplete markets.' Quarterly Journal of Economics, vol. 101(May), pp. 229-64.

Hansmann, H. (1996). 'The changing roles of public, private, and nonprofit enterprise in education, health care and other human services.' In Individual and Social Responsibility: Child Care, Education, Medical Care, and Long-Term Care in America (ed. V. Fuchs), pp. 245-75. Chicago: University of Chicago Press.

Hart, O., Shleifer, A., and Vishny, R. (1997). 'The proper scope of government: theory and and application to prisons.' Quarterly Journal of Economics, vol. 112(4), pp. 1127-61.

Kremer, M. and Sarychev, A. (1998). 'Why do governments operate schools?' Unpublished manuscript, Harvard University.

Levin, H. (1998). 'Educational vouchers: effectiveness, choice, and costs.' Journal of Policy Analysis and Management, vol. 17(3), pp. 373-92.

Poterba, J. (1996). 'Government intervention in the markets for education and health care: how and why?' In Individual and Social Responsibility: Child Care, Education, medical Care, and Long-Term Care in America (ed. V. Fuchs), pp. 277-307. Chicago: University of Chicago Press.

Salamon, L. and Anheier, H. (1998). 'The third route: government-nonprofit collaboration in Germany and the United States.' In Private Action and the Public Good (eds. W. Powell and E. Clemens), pp. 151-62. New Haven: Yale University Press.

Sappington, D. and Stiglitz, J. (1987). 'Privatization, information, and incentives.' Journal of Policy Analysis and Management, vol 6(4), pp.567-82.

Schlesinger, M. (1998). 'Mismeasuring the consequences of ownership: external influences and the comparative performance of public, for-profit, and private nonprofit organizations.' In_Private Action and the Public Good (eds. W. Powell and E. Clemens), pp. 85-113. New Haven: Yale University Press.

Shleifer, A. (1998). 'State versus private ownership.' Journal of Economic Perspectives, vol 12(4), pp.133-50.

Starr, P. (1989). 'The meaning of privatization.' In Privatization and the Welfare State (eds. S. Kamerman and A. Kahn), pp. 15-48. Princeton: Princeton University Press.

Stiglitz, J. (1989). The Economic Role of the State. Oxford: Basil Blackwell, Inc. 
Tobin, J. (1970). 'On limiting the domain of inequality.' Journal of Law and Economics, vol 13 (October), pp. 263-77.

Vining, A. and Boardman, A. (1992). 'Ownership versus competition: efficiency in public enterprise.' Public Choice, vol 73, pp.205-239.

Weisbrod, B. (1998). 'Institutional form and organizational behavior.' In Private Action and the Public Good (eds. W. Powell and E. Clemens), pp. 69-84. New Haven: Yale University Press.

Weisbrod, B. (1988). The Nonprofit Economy. Cambridge: Harvard University Press.

Wolf, C. (1988). Markets or Governments: Choosing Between Imperfect Alternatives. Cambridge, MA: MIT Press. 
Table 1. Models of Public/Private Interaction by Types of Market Failure

\section{Distributnl Agency Unobservable}

Externalities $\underline{\text { Concerns }}$ Problems $\underline{\text { Output Quality }}$

1. Private sector owns Yes

No

No

No

\& manages,

$\mathrm{w} /$ regulation

2. Private sector owns Yes

Yes

No

No

$\&$ manages, w/ regulation

$\&$ vouchers

3. Public sector owns/ private manages

Yes

Yes

Yes

No

4. Public

sector owns

Yes

Yes

Yes

Yes

\& manages 


\section{Fig. 1 Government Involvement in Key Social Services}

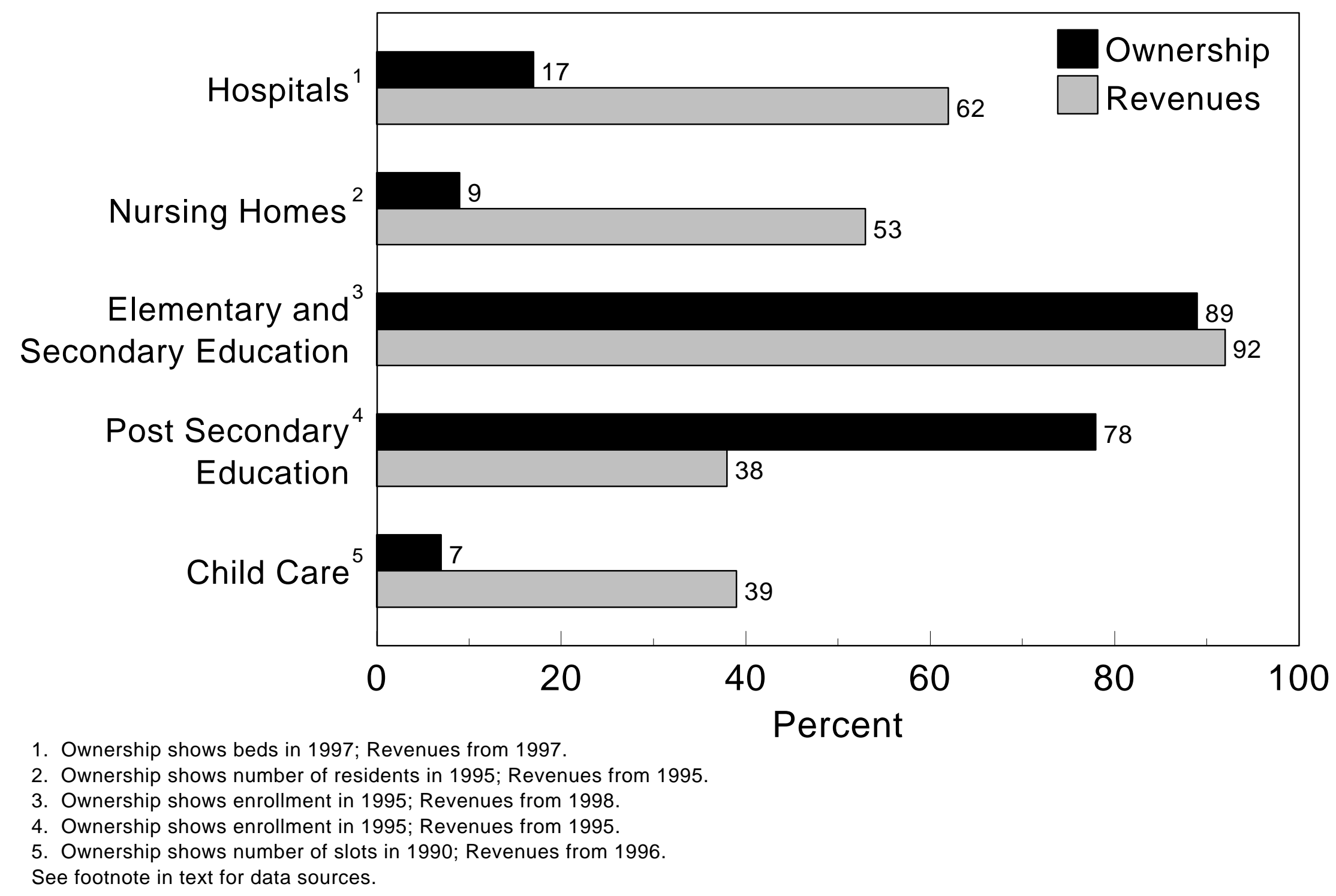

